\title{
ESPACIOS NATURALES EN ZONAS URBANAS Análisis comparado de la ciudad alemana de Halle y las chilenas de San Pedro de la Paz y Talcahuano
}

\author{
NATURAL AREAS IN URBAN LANDSCAPES \\ A comparative Analysis of the German City of Halle and the Chileans \\ of San Pedro de la Paz and Talcahuano
}

\author{
Carlos Priego González de Canales \\ IESA-CSIC, Córdoba. España \\ cpriego@iesa.csic.es \\ JÜRgEN H. BREUSTE
}

Paris - Lodron University Salzburg, Dept. Geography/Geology. Austria

juergen.breuste@sbg.ac.at

\section{JoRge RoJAs HERNÁNDEZ}

Facultad de Ciencias Sociales. Universidad de Concepción. Chile

jrojas@udec.cl

\begin{abstract}
RESUMEN
Con el objetivo de estudiar la percepción social y la valoración de la naturaleza por personas de diferente estrato social y en ciudades de diferente cultura, se inició un proyecto de cooperación internacional entre Alemania y Chile. Para la realización de este proyecto comparativo se escogieron barrios de clase media-alta y media-baja en cada uno de los países. En Alemania se estudiaron los barrios de Silberhöhe y Paulusviertel de la ciudad de Halle, y en Chile el sector de Tumbes (Comuna de Talcahuano) y la Comuna de San Pedro de la Paz, VIII Región del Biobío. La herramienta base para el estudio fue la aplicación de una encuesta base con las mismas preguntas para cada uno de los países. Se determinó cómo las personas de diferentes procedencias sociales y culturales presentaban un diferente uso y percepción del paisaje urbano. De la misma manera, en Chile la condición social del ciudadano condiciona la posibilidad de acceso a áreas verdes y de recreo.
\end{abstract}

\section{Palabras Clave}

Ecología Urbana, Naturaleza Urbana, Percepción Social de la naturaleza.

\section{Abstract}

In order to study the social perception and valorization that people of different social statuses and different cultural cities have about nature, an international cooperative project was started between Germany and Chile. Due to the comparative nature of the project, districts of upper-middle and lower-middle class neighborhoods 
in both countries were chosen. In Germany, two neighborhoods (Silberhöhe and Paulusviertel) were chosen from the city of Halle whereas in Chile one neighborhood from the city of Talcahuano (Tumbes) and the city of San Pedro de la Paz (both in the Region VIII, Biobío) were selected. People from all four study areas were surveyed with the same questions. The results revealed a differential use and perception of the urban landscape by people of different social and cultural backgrounds. Likewise, in Chile a person's social condition was found to determine the possibility of his/her access to green areas and recreational zones.

\section{KEYWORDS}

Social Perception of Nature, Urban Ecology, Urban Nature.

\section{INTRODUCCIÓN}

El fuerte crecimiento urbano experimentado a nivel mundial en las últimas décadas, ha transformado profundamente el paisaje, afectando de forma considerable a los sistemas ecológicos de las ciudades (Sukopp \& Werner, 1983; McDonnell et al., 1997; Breuste \& Wohlleber, 1998; Baker et al., 2001). Dado que el impacto negativo de las ciudades en los ecosistemas puede ser, y de hecho lo es, bastante significativo (Douglas, 1983), mucho se podría aprender aplicando los conceptos de biodiversidad al ecosistema urbano (Savard et al., 2000). Algunos autores señalan incluso la correlación positiva entre un aumento de la biodiversidad de los ecosistemas urbanos -incorporando zonas verdes en las calles y barrios- y la conciencia ambiental de su población, ya que, de acuerdo con algunas evidencias empiricas, los individuos que tienen la oportunidad de relacionarse directamente con la naturaleza en su vida diaria, adquieren mayor sensibilidad ante los problemas relativos a la protección del medio ambiente (Sebba, 1991; Rohde \& Kendle, 1994).

Grandes esfuerzos internacionales se realizan para preservar la naturaleza, principalmente aquellos espacios relativamente intactos y salvajes cuyo valor radica en la gran cantidad de biodiversidad que albergan o en las especies en peligro de extinción que conservan. Sin embargo, se le presta escasa atención a los espacios naturales urbanos, constituidos en los entornos cercanos a los lugares donde la población vive y trabaja (Chiesura, 2004). El desinterés por estos espacios naturales se refleja en el bajo esfuerzo presupuestario que dedican los ayuntamientos de muchas ciudades a la creación y gestión de zonas verdes en sus barrios y comunidades vecinales (Tyrvainen \& Vaananen, 1998).

No obstante, se reconoce cada vez más que la existencia de zonas verdes y parques urbanos es un factor de suma importancia en la calidad de vida de las ciudades, entendida como una combinación de las condiciones del medio ambiente (calidad del aire y del agua, nivel de ruido, tipo de vivienda, accesibilidad, etc.) y de los niveles de bienestar alcanzados en algunos atributos intrínsecos de la persona (salud, educación, etc.) (Pacione, 2003; Hills, 1995; Benzeval et al., 1995). Además, las tensiones sociales generadas en las barriadas periféricas de las grandes ciudades -como los recientes conflictos desencadenados en la banlieu parisina con la quema de coches por parte de jóvenes residentes en las áreas periféricas de París - hacen que los responsables 
políticos y los planificadores urbanos propongan modificar el paisaje de estas áreas introduciendo zonas verdes que, en una especie de greening process, contribuyan al esparcimiento de los vecinos y faciliten la convivencia y sociabilidad entre ellos.

La constatación de que la ciudadanía se preocupa cada vez más por los asuntos relativos a la calidad del medio ambiente en sus propias áreas de residencia, despertó el interés de ecólogos, antropólogos, biólogos, geógrafos y sociólogos por la importancia que los espacios verdes urbanos tienen para las condiciones de vida en las ciudades, dando lugar a numerosos estudios, tanto en el campo de las ciencias ambientales (Akbari et al., 1992; Santibáñez \& Uribe, 1993; McPherson et al., 1995; MacDonald, 1996; Peck \& Callaghan, 1999; Nowak et al., 2000), como de la economía (Selia \& Anderson, 1982 y 1984; Anderson \& Cordell, 1988; McPherson, 1991) y la sociología (Jacobs, 1961; Ulrich, 1984; Chenoweth \& Gobster, 1990; Dwyer et al., 1992; Kaplan, 1993; Brunson et al., 1998a y 2001; Kuo \& Sullivan, 1999 y 2001). El hecho de que se vea en este greening urban process una manifestación del avance de los valores postmaterialistas en la población y que estos valores aparezcan identificados con las sociedades industriales avanzadas (Inglehart, 1991) explica que la práctica totalidad de estos estudios estén centrados en la realidad de los países desarrollados.

Insistiendo en los efectos positivos de las áreas verdes sobre la conciencia ambiental de la población, Hough (1989) argumenta que la presencia de espacios naturales en los entornos cotidianos de los hogares tiene gran importancia en el comportamiento y sensibilidad de los ciudadanos respecto a los temas relacionados con el medio ambiente. En esa misma línea, Miles et al. (1998) señalan que trabajar en contacto directo con la naturaleza constituye, a iguales condiciones laborales, una gran fuente de satisfacción para los trabajadores.

Puede decirse, por tanto, que la presencia de árboles y plantas es un poderoso elemento de identificación de los residentes de un barrio con sus espacios públicos, favoreciendo la construcción de valores comunes y creando vínculos sociales entre los ciudadanos (Lewis, 1992), idea que conecta con los enfoques del capital social aplicados a las áreas urbanas. La contribución del medio ambiente a la creación de capital social, viene avalada por los estudios de Lewis (1996), Berman (1997), que demostraron cómo el vecindario residente en barrios con programas de urbanización basados en la creación de áreas verdes aumenta sus interacciones sociales y desarrolla un alto sentido de identidad y valores compartidos, al tiempo que experimenta un elevado nivel de gratificación. Del mismo modo, Kuo et al. (1998a) encontraron que, en los espacios públicos donde había más vegetación, los lazos sociales entre los visitantes eran más fuertes que los desarrollados entre ciudadanos que vivían alejados de zonas verdes. No obstante, otros estudios señalaron que la influencia de las zonas verdes urbanas en el aumento de los lazos sociales entre los ciudadanos sólo tiene éxito si la comunidad se ve implicada en la participación, uso, disfrute y creación de estos espacios naturales (Hester, 1984).

A lo largo de la década de los 90 del pasado siglo XX, muchas ciudades incorporaron en sus programas ambientales actividades de contacto con la naturaleza, diseñadas con 
el objetivo de contribuir a un incremento del sentido de la identidad social en los barrios y de generar beneficios psicológicos en sus residentes (Ulrich, 1976; Miles et al., 1998). Detrás de estos programas subyace la idea de que si los ciudadanos participan junto a otras personas en la mejora de las condiciones de vida en sus barrios se convencen a sí mismos de que pueden cambiar y controlar las condiciones de su propio entorno (Dwyer, 1995; Kuo et al., 1998b). Este planteamiento sigue en cierto modo la tesis ya demostrada por Park y la Escuela de Chicago (1915) según la cual la ciudad no es un conjunto 0 unidad socialmente homogénea, sino que está formada por subunidades diferenciadas entre sí, tanto en lo relativo a los modos de vida, como a las características sociodemográficas de sus distintos grupos sociales y a la estructura que ocupan en el espacio urbano (Jon, 1989). De acuerdo con esta tesis, cabe esperar que los individuos de una comuna o barrio presenten rasgos de cierta similitud en sus percepciones, actitudes, valores y comportamiento ante determinados asuntos, entre ellos los temas relacionados con el medio ambiente y el uso de los espacios verdes urbanos; asimismo, cabe esperar que las actitudes y comportamiento de los individuos de un mismo barrio difieran de los de las poblaciones que residen en zonas con otras culturas y con niveles económicos y sociales diferentes.

Cada vez adquiere más importancia en los debates públicos la idea de que el desarrollo sostenible de las ciudades no es simplemente mejorar sus aspectos bióticos y abióticos, sino preocuparse por otros aspectos de la vida en la ciudad, como por ejemplo el grado de satisfacción subjetiva de los residentes con su propio entorno, las experiencias cotidianas con la naturaleza, la percepción de la calidad del medio ambiente en sus barrios o el comportamiento proambiental de los ciudadanos (Beer, 1994).

En el contexto de nuestra investigación, la relación entre espacios verdes urbanos y ciudad sostenible se ha enfocado desde la tesis más general según la cual el greening process de las ciudades tiene efectos positivos en la calidad de vida de los ciudadanos (Prescott-Allen, 1991), planteándonos preguntas como las siguientes: ¿cómo percibe el medio ambiente la población que no tiene acceso a espacios naturales? ¿Le dan la misma importancia a la naturaleza y el medio ambiente las personas ricas y las pobres? ¿Cómo son percibidos y utilizados los espacios verdes urbanos en comunidades o barrios de diferentes culturas o nacionalidades? La hipótesis de partida es que las diferentes percepciones, usos y comportamientos de la población hacia el paisaje y los espacios naturales urbanos están condicionados por el estatus socioeconómico y cultural de los usuarios, planteándose su contrastación empírica analizando cuatro barriadas de diferentes condiciones socioeconómicas y ubicadas en países con distintos entornos culturales: Alemania y Chile.

Así pues, el objetivo general de este proyecto de investigación comparativo entre Chile y Alemania consiste en demostrar cómo, en determinados casos, el contexto geográfico (lugar de residencia del encuestado) influye en la percepción y valoración de los espacios verdes urbanos, y cómo, en otros casos, son las raíces culturales y socioeconómicas (país y clase social) las que tienen mayor influencia. 
Los objetivos específicos del proyecto son los siguientes:

- Estudiar las actitudes y comportamientos de los ciudadanos respecto a los espacios verdes urbanos.

- Determinar la valoración de la naturaleza por los usuarios en cada una de las zonas de estudio.

- Estudio del tipo de uso y preferencias de los ciudadanos por los espacios verdes urbanos.

\section{Metodología}

Con el fin de investigar empíricamente el comportamiento, aprovechamiento y uso de los recursos naturales urbanos en sectores de diferente estructura económica y social se seleccionaron diversos espacios urbanos en países con modelos de desarrollo y culturas diferentes: Alemania, como ejemplo de país desarrollado, vinculado a la cultura anglosajona, y Chile, como ejemplo de un país intermedio en vías de desarrollo, vinculado a la cultura latinoamericana. La selección de estos dos países se explica por la preexistente cooperación entre el instituto de investigación UFZ-Umweltforschungszentrum de Leipzig-Halle (Alemania) y el Centro de Ciencias Ambientales EULA, de Concepción (Chile). Dentro de estos países se eligieron las ciudades donde estaban ubicados sendos centros: Concepción, en el caso de Chile y Halle, para el alemán. La selección de las cuatro zonas de estudio fueron los barrios alemanes Paulusviertel y Silberhöhe (ambos, en la ciudad de Halle, situada en uno de los länder de la antigua Alemania del Este), y las comunas chilenas de San Pedro de la Paz y Talcahuano (ambas, en las conurbaciones de la ciudad de Concepción, perteneciente a la VIII Región) (figuras 1 y 2). Los criterios para seleccionar estos barrios fueron los siguientes:

Que tanto los barrios seleccionados en Chile como los seleccionados en Alemania fueran barrios próximos entre sí, para que se vieran influenciados por la misma cultura local y regional. De este modo, se cumplía el requisito de que existieran diferencias culturales entre los barrios alemanes y chilenos seleccionados, pero no entre los dos barrios de cada país.

Que los cuatro barrios tuvieran una alta densidad de población, pero que existieran diferencias socioeconómicas entre ellos, tanto en los dos chilenos entre sí (lo que resultó relativamente fácil dada la desigualdad económica existente en la ciudad de Concepción), como entre los dos barrios alemanes (cosa más difícil, debido a las menores diferencias sociales en Halle).

Que estuvieran dotados de zonas verdes cuyo diseño fuera común a otras ciudades, garantizando así el valor sociológico de la investigación al evitar que los casos estudiados fueran excepcionales.

Que en los cuatro barrios existieran zonas verdes de fácil acceso para los usuarios.

Que en las cercanías de cada barrio (máximo 10 a 15 minutos andando) existieran zonas de naturaleza silvestre o poco intervenidas por el hombre. Para el caso chileno, las áreas verdes cercanas a la comuna de San Pedro de la Paz son la "Laguna Chica" y 
la "Laguna Grande"; y en la comuna de Talcahuano la zona verde es el "Parque Tumbes". En la ciudad alemana de Halle, las áreas verdes son el parque natural "Galgenberg" en el barrio de Paulusviertel, y el humedal de "Saale-Elster" en el barrio de Silberhöhe.

Cada una de las áreas de estudio presenta un tipo arquitectónico particular y una marcada diferenciación socioeconómica. Las dos áreas de mayor nivel socioeconómico (Paulusvierte, I en Alemania y San Pedro de la Paz, en Chile) se compararon con las dos de menos nivel (Silberhöhe, en Alemania y Talcahuano, en Chile), permitiendo analizar la influencia de la variable socioeconómica en la percepción y aprovechamiento de los espacios naturales urbanos. Al ser, además, áreas de estructuras arquitectónicas diferentes, la comparación permite ver también la influencia del tipo de entorno residencial en dichas percepciones y aprovechamientos del espacio natural. En un anejo, al final del artículo, se presentan con detalle las características de cada zona de estudio.

\section{Utilización de los Criterios Sociales y su aplicación en la encuesta}

En las cuatro áreas geográficas seleccionadas, y utilizando la base metodológica de los 20 Criterios Sociales de la Unión Europea, elaborados en el Programa Europeo URGE 2001 (Urban Green Environment) (tabla 1), se planteó el proyecto de investigación germano-chileno con el objetivo de analizar los efectos que tienen aspectos como la cultura y el nivel socio-económico de la población en la relación de los ciudadanos con los espacios verdes urbanos.

Según el modelo proporcionado por los 20 Criterios Sociales, el análisis de los aspectos sociales de los espacios verdes urbanos suele realizarse mediante entrevistas dirigidas a los usuarios reales o potenciales de tales espacios, en las que se recaba información sobre la percepción y significado que tienen y sobre las motivaciones que los impulsan a acudir a esas áreas de esparcimiento (Bussey, 1996). El acceso a los espacios verdes urbanos está relacionado con el estilo de vida de cada usuario, así como con los beneficios esperados en lo que respecta a la tranquilidad frente al estrés, a los recuerdos y emociones, a la relación con amigos y familiares $u$ otros tipos de beneficios sugeridos por los entrevistados (Bussey, 1996; Coles \& Bussey, 2000).

De entre los siete grandes bloques temáticos que agrupan a los 20 Criterios Sociales se escogieron los tres que mejor respondían a la finalidad del estudio: "Calidad de Vida", "Comunidad e Identidad Local" $y$ "Seguridad e Inclusión Social". A su vez se seleccionaron de cada uno de estos tres bloques aquellos Criterios Sociales que definían los objetivos del estudio: "Necesidades diarias de recreación", "Uso óptimo de los espacios verdes locales", "Localización", "Identidad con espacios verdes locales" e "Inclusión Social"

Los cinco Criterios Sociales seleccionados fueron operacionalizados en un cuestionario, cuyo contenido quedó estructurado en cinco apartados diferentes, los cuales contenían un conjunto de preguntas.

Todos estos grupos de preguntas fueron planteados con el objetivo de analizar las relaciones con los espacios naturales urbanos de ciudadanos de diferentes estratos sociales, cultura, infraestructura habitacional y edades, así como de comprobar cómo se 
Tabla 1.

Criterios para analizar los aspectos sociales de los espacios verdes urbanos.

\begin{tabular}{lcl}
\hline Bloques temáticos & \multicolumn{1}{l}{ Criterios Sociales } \\
\hline Calidad de vida & 1 & $\begin{array}{l}\text { Promoción de alta calidad de vida y } \\
\text { buenas condiciones de trabajo }\end{array}$ \\
& 2 & $\begin{array}{l}\text { Necesidades diarias de recreación } \\
\text { Estrategias vitales }\end{array}$ \\
Salud y bienestar & 3 & Salud física y buen estado emocional \\
& 4 & Refugios contra el estrés, tranquilidad y relax en la vida urbana \\
Educación y & 5 & Exploración del mundo natural \\
habilidad personal & 6 & Entendimiento del medio ambiente urbano \\
& 7 & Fuentes educacionales \\
Comunidad, Identidad local & 9 & Uso óptimo de los espacios verdes locales \\
& 10 & Localización \\
& 11 & Propiedad de la comunidad \\
Seguridad & 12 & Identidad con los espacios verdes locales \\
e inclusión social & 13 & Miedo del crimen, uso seguro de los \\
& 14 & espacios verdes urbanos \\
Recreación, & Inclusión social \\
ocio y deporte & 15 & Actividades de recreación \\
Ayuda, & 16 & Facilidades para el deporte \\
gerencia y finanzas & 17 & Eventos familiares o comunitarios \\
& 18 & Gestión \\
& 19 & Experiencia \\
& 20 & Financiación \\
\hline
\end{tabular}

Fuente: Programa Europeo URGE 2001.

utilizan y aprovechan con fines recreativos las áreas verdes públicas. Asimismo, con la encuesta se ha pretendido estudiar la valoración de los ciudadanos de los componentes paisajísticos naturales del entorno residencial (Kromrey, 1991; Friedrichs, 1992). La metodología utilizada se basa en los trabajos de Austin (2004), Stewart et al. (2004) y Pacione (2003). El análisis de los datos aportó, en definitiva, información interesante para los planificadores urbanos sobre la importancia de considerar la cultura, la identidad y el estrato socioeconómico de los barrios a la hora de diseñar sus espacios verdes. 
Tabla 2.

Criterios Sociales y su operacionalización en la encuesta.

\begin{tabular}{|c|c|c|c|}
\hline Criterios Sociales & Descripción & Grupos de Preguntas & Rol \\
\hline $\begin{array}{l}\text { Necesidades diarias de } \\
\text { recreación }\end{array}$ & $\begin{array}{l}\text { La interacción con los } \\
\text { espacios verdes urba- } \\
\text { nos debería ser conce- } \\
\text { bida como una actividad } \\
\text { diaria. } \\
\text { Los ciudadanos debe- } \\
\text { rían elegir libremente } \\
\text { cuándo desean visitar } \\
\text { estos espacios a lo largo } \\
\text { de la semana o incluso } \\
\text { del año, sin ningún tipo } \\
\text { de obstáculo. }\end{array}$ & $\begin{array}{l}\text { Disposición de tiempo libre } \\
\text { entre semana. } \\
\text { Disposición de tiempo libre } \\
\text { el fin de semana. } \\
\text { Posesión de automóvil. } \\
\text { Uso de automóvil. } \\
\text { Actividades de tiempo } \\
\text { libre. } \\
\text { Lugar de vacaciones. } \\
\text { Posesión de jardín, par- } \\
\text { cela, huerta,... }\end{array}$ & $\begin{array}{l}\text { Observar si todo } \\
\text { el conjunto de la } \\
\text { población presenta } \\
\text { las mismas oportuni- } \\
\text { dades de uso de la } \\
\text { naturaleza. }\end{array}$ \\
\hline $\begin{array}{l}\text { Uso óptimo de los } \\
\text { espacios verdes } \\
\text { locales }\end{array}$ & $\begin{array}{l}\text { El acceso a los espacios } \\
\text { verdes urbanos no debe- } \\
\text { ría estar limitado por } \\
\text { factores que reduzcan } \\
\text { su accesibilidad y uso. } \\
\text { La calidad, forma y can- } \\
\text { tidad de vegetación, así } \\
\text { como la posibilidad de } \\
\text { ofrecer sólo una o diver- } \\
\text { sas funciones al usuario, } \\
\text { hacen que el espacio } \\
\text { tenga o no éxito. }\end{array}$ & $\begin{array}{l}\text { Formas de disfrutar de la } \\
\text { naturaleza. } \\
\text { Frecuencia de visita a las } \\
\text { áreas verdes. } \\
\text { Tiempo de permanencia } \\
\text { en los espacios verdes. } \\
\text { Problemas encontrados } \\
\text { en los espacios verdes. } \\
\text { Valoración de los aspec- } \\
\text { tos naturales del espacio } \\
\text { verde. }\end{array}$ & $\begin{array}{l}\text { Reconocer la calidad } \\
\text { de la naturaleza, y } \\
\text { qué es lo que los } \\
\text { usuarios valoran } \\
\text { más de los espacios } \\
\text { verdes. }\end{array}$ \\
\hline Localización & $\begin{array}{l}\text { El factor más crucial } \\
\text { para acceder a los espa- } \\
\text { cios verdes es que estén } \\
\text { localizados dentro de } \\
\text { una distancia fácil de } \\
\text { recorrer por los usuarios, } \\
\text { siendo la ideal la que } \\
\text { equivale a } 5 \text { minutos } \\
\text { andando. }\end{array}$ & $\begin{array}{l}\text { Ubicación del lugar donde } \\
\text { se observa la naturaleza. } \\
\text { Tiempo de llegada al } \\
\text { parque. }\end{array}$ & $\begin{array}{l}\text { Comprobar si la ubi- } \\
\text { cación de las áreas } \\
\text { verdes urbanas per- } \\
\text { mite la asistencia de } \\
\text { todo tipo de ciuda- } \\
\text { danos o, en cambio, } \\
\text { dificulta su uso por } \\
\text { parte de algún grupo } \\
\text { social (niños, madres } \\
\text { con bebés, mayores, } \\
\text { discapacitados). }\end{array}$ \\
\hline
\end{tabular}


Tabla 2.

Continuación.

\begin{tabular}{|c|c|c|c|}
\hline $\begin{array}{l}\text { Identidad con espacios } \\
\text { verdes locales }\end{array}$ & $\begin{array}{l}\text { La identidad local suele } \\
\text { ser definida por los senti- } \\
\text { mientos que un determi- } \\
\text { nado paisaje despierta } \\
\text { en los individuos. } \\
\text { Estos sentimientos } \\
\text { suelen estar represen- } \\
\text { tados por un refuerzo del } \\
\text { sentido de pertenencia } \\
\text { debido a lazos cultura- } \\
\text { les, históricos u otros. }\end{array}$ & $\begin{array}{l}\text { Significado de la natu- } \\
\text { raleza. } \\
\text { Actitud ante la protección } \\
\text { de la naturaleza. } \\
\text { Disposición a invertir en la } \\
\text { protección de naturaleza. } \\
\text { Participación en activida- } \\
\text { des de protección de la } \\
\text { naturaleza. } \\
\text { Nombre del parque que } \\
\text { normalmente visita. } \\
\text { Tipo de barrio de resi- } \\
\text { dencia. }\end{array}$ & $\begin{array}{l}\text { Conocer la importan } \\
\text { cia que se les da } \\
\text { los espacios verdes } \\
\text { urbanos y, como con } \\
\text { secuencia, la concien } \\
\text { cia ambiental de los } \\
\text { usuarios. } \\
\text { Estudiar si existen } \\
\text { diferencias entre } \\
\text { usuarios de diferentes } \\
\text { estratos sociales. }\end{array}$ \\
\hline Inclusión social & $\begin{array}{l}\text { El acceso a las áreas } \\
\text { verdes urbanas debe } \\
\text { ser independiente de } \\
\text { la edad, el género, el } \\
\text { estatus, la educación o } \\
\text { la renta. } \\
\text { El acceso, localización, } \\
\text { tamaño, calidad y ges- } \\
\text { tión del espacio natural } \\
\text { asegura que los usua- } \\
\text { rios se sientan satis- } \\
\text { fechos. } \\
\text { Debe ser prioritario } \\
\text { adoptar medidas que } \\
\text { eliminen los factores } \\
\text { negativos que disua- } \\
\text { dan del uso del espacio } \\
\text { natural (sensación de } \\
\text { miedo e inseguridad, } \\
\text { aglomeración,...). }\end{array}$ & $\begin{array}{l}\text { Edad. } \\
\text { Situación laboral. } \\
\text { Grado de escolaridad. } \\
\text { Barrio donde vive. }\end{array}$ & $\begin{array}{l}\text { Comprobar si el usc } \\
\text { de la naturaleza } \\
\text { está diferenciado } \\
\text { por clases sociales } \\
\text { o algún otro condi } \\
\text { cionante. }\end{array}$ \\
\hline
\end{tabular}

Fuente: Programa Europeo URGE 2001. 


\section{Realización de LA Encuesta}

Previamente a la aplicación de la encuesta en las áreas de estudio seleccionadas, todos los hogares incluidos en el muestreo fueron visitados por los entrevistadores y se les pidió su colaboración, entregándoles una hoja informativa donde se explicaba qué institución era la responsable de realizar el estudio, cuáles eran los objetivos del mismo, qué contenido tendría el cuestionario y en qué fecha y hora los entrevistadores irían a realizar la encuesta. El cuestionario se adaptó a las particularidades de cada país, si bien conservando su estructura general y el significado de cada una de las preguntas. En total se plantearon 53 preguntas en los barrios Paulusviertel y Silberhöhe de la ciudad alemana de Halle y 50 en las comunas chilenas de San Pedro de la Paz y Tumbes-Talcahuano. Las preguntas fueron previamente verificadas por medio de una encuesta piloto a 20 personas seleccionadas aleatoriamente en ambos países.

La muestra general de la encuesta se calculó por medio de un muestreo probabilístico aleatorio. El universo de la muestra de Chile fue de 9.601 personas para San Pedro de la Paz (residentes mayores de 18 años de los sectores vecinales de Laguna Grande, Los Arrayanes y Las Acacias) y 12.000 personas para Tumbes-Talcahuano (residentes mayores de 18 años de los sectores vecinales de Los Copihues, Nueva los Lobos, Villa Badarán y Centinela Sur). En el caso alemán, el universo de la muestra fue de 8.600 habitantes para el barrio residencial de Paulusviertel y de 35.000 habitantes para el complejo habitacional 8 WK de Silberhöhe. La aplicación del cuestionario se realizó de distinta manera en Chile y Alemania, debido al diferente tiempo de aplicación, recursos económicos disponibles y también teniendo en cuenta la distinta cultura de participación en encuestas por parte de la población de cada país. En Alemania, los cuestionarios fueron distribuidos personalmente en los hogares seleccionados y recogidos días más tarde por los entrevistadores. Se distribuyeron 1.012 cuestionarios, de los cuales 491 fueron devueltos de manera utilizable (258 en Paulusviertel y 233 en Silberhöhe). En Chile se optó por la encuesta presencial, debido a la poca cultura de la población chilena en la autorrealización de encuestas. El tamaño de la muestra chilena fue de 200 personas para Tumbes y San Pedro de la Paz, y se realizó la totalidad de las encuestas previstas. Con estos reducidos tamaños de muestra es evidente que la encuesta no permite extraer conclusiones significativas desde el punto de vista estadístico, aunque sí tiene un valor indudable para los objetivos exploratorios planteados en la investigación.

\section{RESULTADOS Y DISCUSIÓN}

Para facilitar la comprensión de los resultados, y debido a que muchos de los Criterios Sociales están interconectados entre sí, se decidió agrupar las respuestas en tres grandes apartados temáticos permitiendo, de este modo, tener una explicación más clara sobre los resultados obtenidos. El primer apartado, denominado "La presencia de 
Gráfico 1.

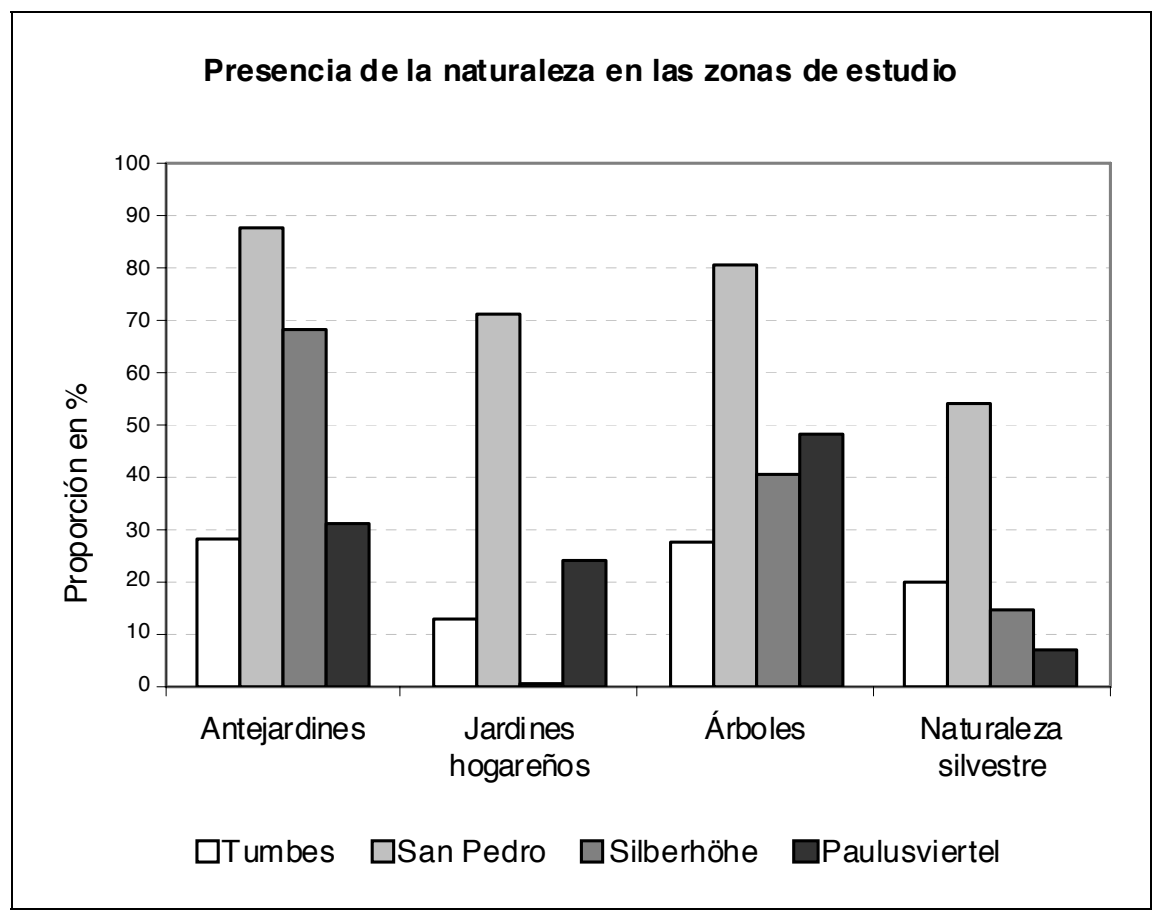

Fuente: Elaboración propia.

la naturaleza en las zonas de estudio", describe los equipamientos naturales en cada una de las zonas de estudio, para posteriormente recoger el grado de satisfacción que los encuestados presentan sobre su entorno natural. El segundo apartado, "Actitudes y comportamientos proambientales", incluye las respuestas a una serie de preguntas sobre actitudes y comportamientos proambientales y la identidad con los espacios verdes locales, es decir, la valoración e importancia que los ciudadanos dan a la naturaleza que les rodea. Para el análisis de la conciencia ambiental el estudio se centró en tres aspectos; "importancia que tienen para el encuestado los temas relacionados con la protección de la naturaleza", "su valoración de la cantidad de dinero que se invierte en proteger la naturaleza" y "su participación en actividades de protección de la naturaleza". El tercer y último apartado temático se refiere al "Uso y preferencia de los espacios verdes", incluyéndose las siguientes cuestiones: tipo de zona verde donde pasea el encuestado; actividad de preferencia en los ratos de tiempo libre; frecuencia de visita a los espacios verdes, y lugar desde donde el encuestado observa la naturaleza. A continuación se presentan los resultados más relevantes. 
a) La presencia de la naturaleza en las zonas de estudio

Aunque se ha procurado que tanto las zonas de estudio seleccionadas en Chile como las de Alemania posean el mismo tipo de espacios naturales urbanos (parques, arbolado, plazas, jardines, etc.), la disposición y estructura paisajística de estos espacios, su superficie y grado de accesibilidad varían de unas áreas a otras, siendo esa diversidad uno de los factores que hay que tener en cuenta en el atractivo que ejercen dichas zonas en los ciudadanos.

Además de esa diversidad en cuanto al contenido de sus espacios naturales, las zonas de estudio varían también en lo que se refiere a la densidad del equipamiento y a la presencia de zonas verdes en el entorno de las viviendas, de modo que hay barrios en donde sus residentes tienen un contacto más directo con la naturaleza que los que residen en otras zonas, independientemente de que usen o no los espacios verdes públicos. En general, la geografía de Chile es, además, rica en paisajes naturales y silvestres, donde abundan áreas de bosques autóctonos, así como lagunas y ríos caudalosos cercanos a la ciudad, lo que imprime su impronta en la cultura de los chilenos; no obstante, y tal como puede verse en el gráfico 1, la intensidad de la interacción varía de unos barrios a otros por razones socioeconómicas. Por ejemplo, el barrio de San Pedro de la Paz

\section{Gráfico 2.}

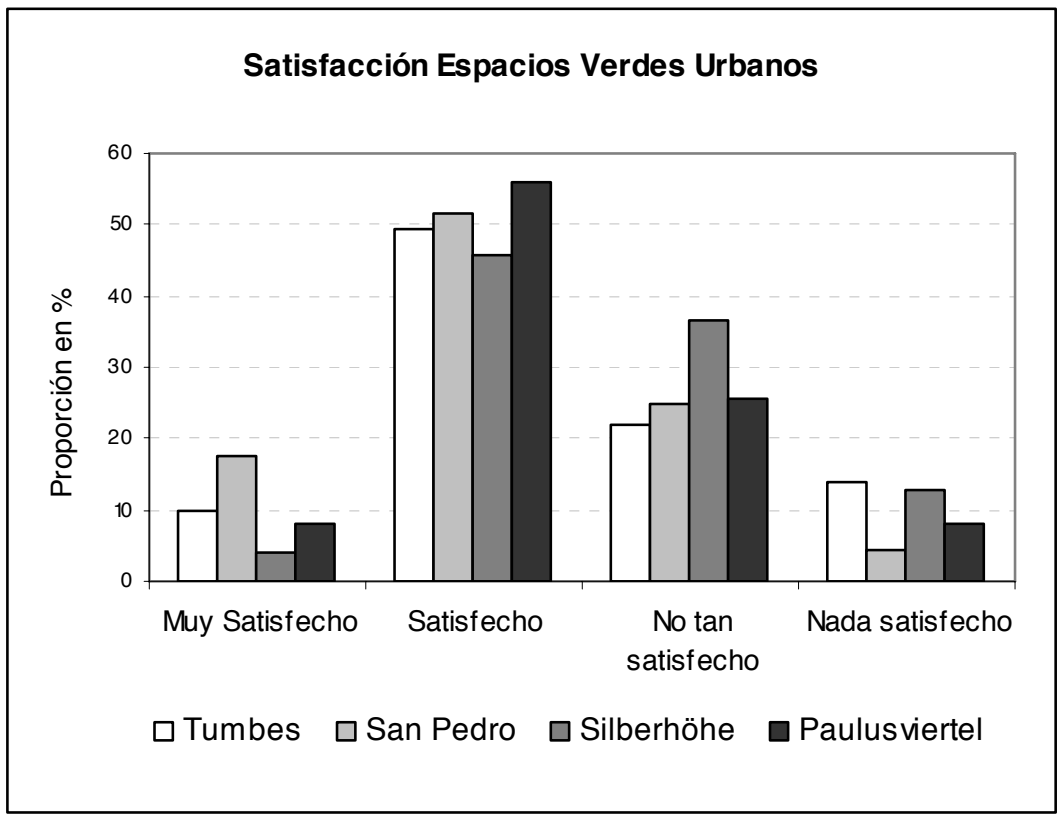

Fuente: Elaboración propia. 
sobresale del resto por su equipamiento natural en todas sus manifestaciones (jardines en el hogar, árboles en las calles, áreas de vegetación silvestre en el entorno del barrio), por lo que sus habitantes estarán más en estrecho contacto con la naturaleza urbana que los habitantes deTumbes, que son más pobres en equipamiento natural. Por el contrario, el patrimonio natural de las ciudades europeas es más reducido, lo que hace que la interacción cotidiana de los ciudadanos con la naturaleza dependa, sobre todo, de que haya espacios verdes urbanos; al igual que en el caso chileno también aquí se observan diferencias entre los barrios de Paulusviertel y Silberhöhe, aunque menos intensas (gráfico 1).

Dado que la cantidad, calidad y ubicación de los espacios verdes urbanos forma parte del patrimonio natural de una ciudad o del barrio donde estén situados, cabe plantear que esos espacios serán motivo de orgullo y satisfacción para los ciudadanos. Para conocer hasta qué punto la carencia o disponibilidad de zonas verdes influye en la satisfacción del ciudadano, se formuló la pregunta "¿Se siente satisfecho con el equipamiento natural de su barrio?". Los mayores porcentajes de satisfacción se dieron en las zonas mejor equipadas de espacios verdes, lo que prueba la validez de la suposición anterior (gráfico 2). Los residentes en San Pedro de la Paz fueron los que expresaron el mayor porcentaje de satisfacción siendo un $69 \%$ la suma de los entrevistados que respondieron sentirse muy satisfechos y satisfechos, seguidos de los de Paulusviertel (64\%), Tumbes $(60 \%)$ y Silberhöhe (50\%). En lo que respecta al grado de insatisfacción, es entre los que viven en los barrios con menos áreas verdes donde se dan los porcentajes más elevados de insatisfechos (la suma de no tan satisfechos y nada satisfechos): Tumbes (36\%) y Silberhöhe (49\%), aunque se percibe aquí la influencia de la cultura chilena, que hace que la insatisfacción en Tumbes se vea algo mitigada, dado que, como veremos más adelante, los residentes en este barrio utilizan con bastante frecuencia las áreas de naturaleza silvestre situadas en la afueras de la ciudad.

\section{b) Actitudes y comportamientos proambientales}

La conciencia ambiental de los ciudadanos suele medirse a través de varias dimensiones: su percepción sobre la importancia del medio ambiente y sus actitudes de apoyo a determinadas políticas de protección de la naturaleza; y su comportamiento tanto en el nivel individual (comportamiento en la vida cotidiana), como en el colectivo (participación en acciones de protesta, voluntariado, apoyo a iniciativas populares a favor del medio ambiente) (Moyano y Jiménez, 2005).

La existencia de espacios verdes urbanos es ampliamente percibida por la población como algo muy importante, alcanzándose porcentajes muy elevados en las cuatro zonas de estudio. Más del $90 \%$ de los encuestados en cada zona dice que la naturaleza es importante para ellos o declaran estar muy unidos a ella (San Pedro de la Paz, 96\%; Tumbes, 98\%; Paulusviertel, 94\%, y Silberhöhe, 98\%). Esto nos podría inducir a pensar que en la actitud hacia la naturaleza no influyen la cultura ni las condiciones socioeconómicas del encuestado, contradiciendo así algunas de las afirmaciones que 
se hacen sobre la importancia de los valores en la percepción del medio ambiente y que señalan que conforme aumenta el nivel de renta y la población se impregna de valores postmaterialistas aumentarían las actitudes positivas sobre la naturaleza. Si fuera así, la población de Tumbes y de Silberhöhe, los barrios más pobres de los cuatro seleccionados, mostraría actitudes menos positivas hacia el medio ambiente. No obstante, las respuestas a otras preguntas no permiten aventurar conclusiones, sino mantener el debate abierto.

En efecto, profundizando en este tema de la conciencia ambiental se analizó la valoración social del esfuerzo que se hace para proteger el medio ambiente, planteándosele al encuestado una serie de opciones de respuestas. En sintonía con la respuesta anterior, la opción más valorada fue la que afirmaba que "La naturaleza tiene un alto coste, pero merece la pena invertir en ella", y la menos valorada la de que "Es preferible invertir ese dinero en resolver otros problemas sociales urgentes". No obstante, se observan diferencias entre las zonas de estudio en la intensidad de las respuestas. Así, en los barrios chilenos fue donde se manifestaron los mayores porcentajes de apoyo a la opción proambiental (San Pedro de la Paz, con el 84\% de apoyo, y Tumbes, con el $77 \%$; frente al $58 \%$ de Paulusviertel y al $55 \%$ de Silberhöhe). Entre los barrios chilenos se observan algunas diferencias en función de sus respectivos niveles socioeconómicos, de modo que en el rico barrio de San Pedro de la Paz la conciencia ambiental es mayor

Gráfico 3.

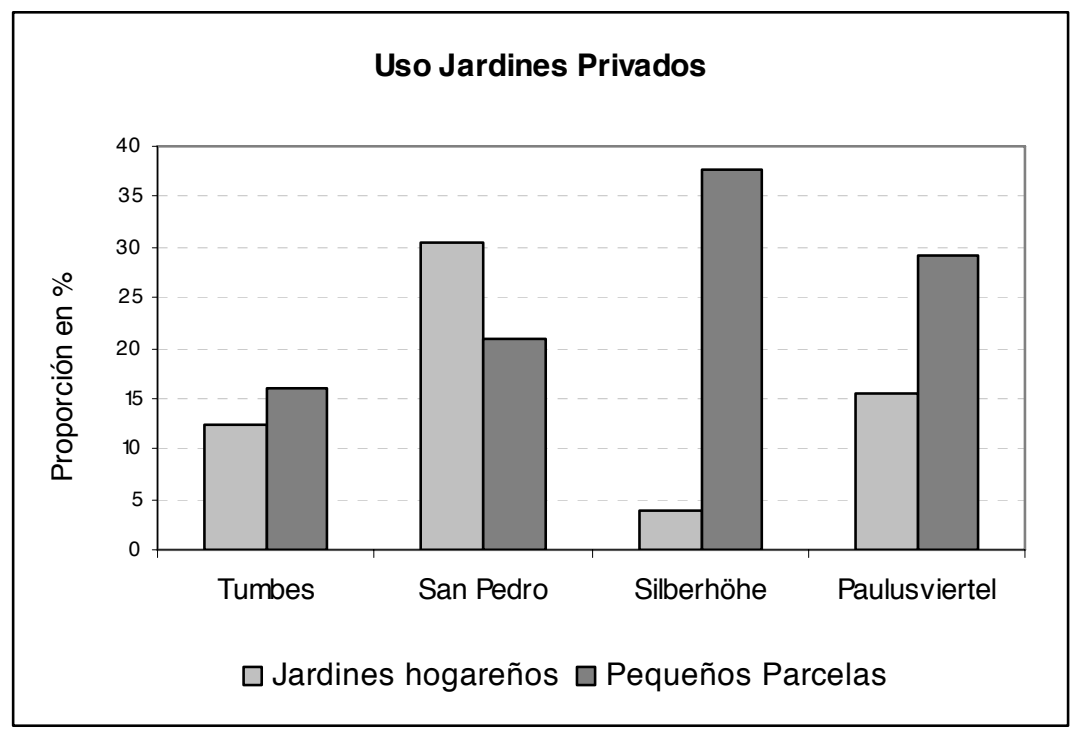

Fuente: Elaboración propia. 
que en el más pobre de Tumbes, ocurriendo lo mismo, aunque con menos intensidad, entre los dos barrios alemanes. Vemos, por tanto, que la variable socioeconómica ejerce influencia en esta dimensión de la conciencia ambiental (a mayor renta, más conciencia ambiental), pero matizada cuando interviene la variable cultural (a igual renta, los barrios chilenos de San Pedro de la Paz y Tumbes muestran mayor conciencia ambiental que los alemanes de Paulusviertel y Silberhöhe, respectivamente); esta variable cultural incluso puede llegar a neutralizar la influencia de la variable socioeconómica.

El mayor grado de conciencia ambiental en las zonas de estudio chilenas quedó también corroborado por las respuestas a las preguntas referidas a la dimensión de comportamiento. En efecto, preguntados los encuestados por su grado de participación en algunas medidas de protección de la naturaleza, y comparando los dos barrios de mayor nivel de renta, vemos que el $29 \%$ de los habitantes de la comuna chilena de San Pedro de la Paz dice haber participado alguna vez en acciones destinadas a la conservación de la naturaleza, frente al $24 \%$ del barrio alemán de Paulusviertel; comparando los dos barrios más pobres, se observa que es mayor el grado de participación de los residentes en la comuna chilena de Tumbes (22\%), que el de los que residen en el barrio alemán de Silberhöhe (16\%). Si además tenemos en cuenta que en el barrio pobre de Tumbes sus habitantes gozan de menos tiempo libre para dedicarse a actividades de la naturaleza, el indicador de conciencia ambiental adquiere aún mayor relevancia.

Los datos permiten probar la influencia de la variable socioeconómica en la conciencia ambiental, pero aconsejan debatir sobre el sentido de la influencia de la variable cultural. Da la impresión de que la cultura influye, pero no en el sentido de los valores postmaterialistas señalados por autores como Inglehart (1991) o de los valores políticos apuntados por los autores que estudian la influencia de las políticas de desarrollo sostenible ligadas al Estado del Bienestar (Garrido, 2000) o la influencia del movimiento ecologista o de los partidos verdes en la conciencia ambiental de los ciudadanos (Yearly, 1992). La influencia de la cultura se manifiesta en un sentido más antropológico, es decir, más profundo y menos coyuntural, ligado a la relación tradicional de cada país con la naturaleza y el medio ambiente. La tradición proambiental de la cultura chilena influye más en la conciencia ciudadana a favor de la naturaleza que el avance de los valores postmaterialistas en Alemania, o la mayor presencia de las políticas de desarrollo sostenible en este país europeo.

\section{c) Uso y preferencia de los espacios verdes}

Las respuestas relativas al uso y aprovechamiento de los espacios verdes urbanos señalan que, en este aspecto del comportamiento, influye más el nivel socioeconómico de los ciudadanos y la estructura de oportunidades de que disponen, que la tradición cultural de cada país. En efecto, ante la pregunta " ¿En qué área verde pasa usted normalmente su tiempo libre?" (gráfico 4), el 52\% de los ciudadanos de San Pedro de la Paz dice que utiliza sobre todo los jardines privados y las parcelas de fin de semana, frente al $29 \%$ de Tumbes, el $45 \%$ de Paulusviertel y el $42 \%$ de Silberhöhe. 
Gráfico 4.

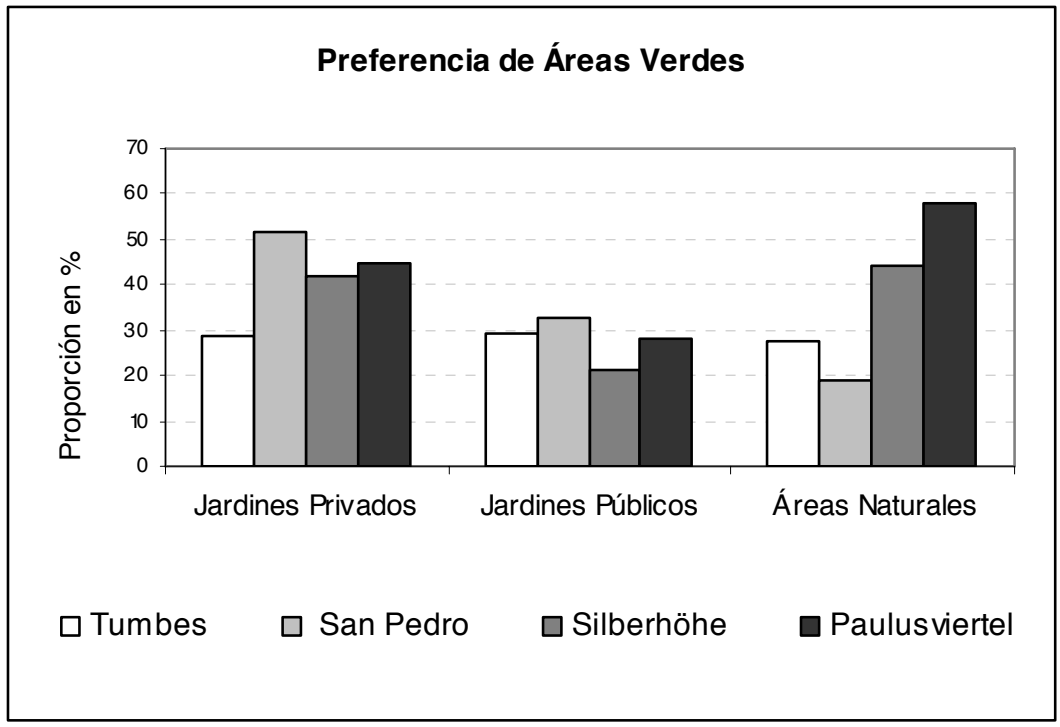

Fuente: Elaboración propia.

Si comparamos los dos barrios chilenos se observa con claridad la influencia de la variable socioeconómica y de la estructura de oportunidades por cuanto que los residentes en el barrio de San Pedro de la Paz, al tener mayores opciones de disponer de jardines en sus casas o de parcelas de fin de semana que los de Tumbes, expresan una mayor frecuencia de uso de esos espacios verdes de naturaleza privada. Entre los dos barrios alemanes, sin embargo, las diferencias son menores, ya que el menor nivel de renta de los residentes en Silberhöhe (y por tanto sus menores posibilidades de contar con jardines en el hogar o parcelas de fin de semana) es compensado con la oferta de zonas ajardinadas de uso privado que hace el ayuntamiento de la ciudad de Halle (los Ilamados Allotment Gardens) ${ }^{1}$, igualando así la estructura de oportunidades de la población. Este factor de naturaleza política explicaría también las diferencias entre los barrios de Tumbes y Silberhöhe, que siendo los de más bajo nivel de renta gozan de diferentes oportunidades a la hora de disfrutar de los espacios verdes privados.

Respecto a los espacios verdes de uso público (parques, jardines o áreas de naturaleza silvestre), también influyen estas variables (gráfico 4). Los residentes en

\footnotetext{
${ }^{1}$ Estos jardines públicos de uso privado (de no más de 50 metros cuadrados y de concesiones temporales) están diseminados por el centro de la ciudad o sus alrededores. La finalidad y uso de estos pequeños jardines son exclusivamente para el cultivo de frutales, flores ornamentales y hortalizas para autoconsumo.
} 
comunas chilenas muestran una mayor preferencia por los jardines públicos que los que residen en los barrios alemanes: un 32\% en San Pedro de la Paz (su segunda opción, detrás de las parcelas o jardines privados) y un 30\% en Tumbes (su primera opción, aunque muy similar a la opción de usar las parcelas o jardines privados), frente al $27 \%$ de los residentes en Paulusviertel (su última opción) y al 21\% de los de Silberhöhe (también su última opción).

Estos datos muestran que, además del nivel socioeconómico del barrio de residencia (en los de mayor nivel de renta es más elevada la preferencia por los espacios verdes privados que por los jardines públicos), la tradición cultural del país y la estructura de oportunidades ejercen una influencia significativa: si comparamos el barrio chileno con alto nivel de renta de San Pedro de la Paz con su equivalente alemán Paulusviertel, vemos que en éste es menor la preferencia por los jardines públicos, ocurriendo lo mismo si se comparan los barrios más pobres de Tumbes en Chile y de Silberhöhe en Alemania; quizás la ya mencionada oferta de espacios para uso privado (los Allotment Gardens del ayuntamiento de la ciudad de Halle) podría explicar que, con similares niveles socioeconómicos, los residentes en Paulusviertel y Silberhöhe prefieran menos los jardines públicos que los que residen en San Pedro de la Paz y en Tumbes.

Otra de las preguntas estuvo relacionada con las preferencias de los encuestados sobre las "actividades preferidas fuera del hogar en su tiempo libre". La respuesta "pasear por los parques o jardines públicos cercanos al hogar" fue la más citada en todos los barrios de ambos países (San Pedro de la Paz 54\%, Tumbes 62\%, Paulusviertel $52 \%$, Silberhöhe 50\%) (gráfico 5). Si comparamos las dos comunas chilenas vemos claramente la influencia de la variable socioeconómica, de modo que allí donde el nivel de renta es más bajo (y por tanto, las viviendas disponen de menos jardines privados) el esparcimiento se hace con más frecuencia en los espacios públicos, lo que explicaría el mayor porcentaje en Tumbes (62\%) de los que citan esa respuesta. Sin embargo, entre los barrios alemanes se invierte esa tendencia, de modo que es en el rico barrio de Paulusviertel donde se da un porcentaje mayor de los que eligen la opción de pasear por los parques o jardines públicos (52\%). Este cambio sólo podría explicarse por la variable política, ya que la oferta de jardines de uso privado por parte del ayuntamiento de la ciudad de Halle mitigaría el efecto de la variable socioeconómica hasta el punto de que los que residen en Silberhöhe aprovechan esos espacios privados más que los de Paulusviertel (que si bien tienen jardines en sus hogares, buscan el esparcimiento en los espacios verdes públicos cuando tienen tiempo libre).

La segunda actividad más valorada en los barrios de altos ingresos chilenos y alemanes para pasar su tiempo libre fue la de "pasear por las calles del barrio que tengan árboles" (un 47\% cita esta respuesta en San Pedro de la Paz y un $47 \%$ en Paulusviertel), no ocurriendo lo mismo en los barrios de menos nivel ingresos (un $28 \%$ en Tumbes y un $17 \%$ en Silberhöhe) (gráfico 5), lo que prueba la influencia de la variable socioeconómica en esas preferencias; esta influencia iría en la dirección de que en los barrios con menos nivel de renta las calles no suelen tener arbolado, y si lo tienen, es de peor calidad paisajística que en los barrios de mayor nivel socioeconómico, lo que haría 
Gráfico 5.

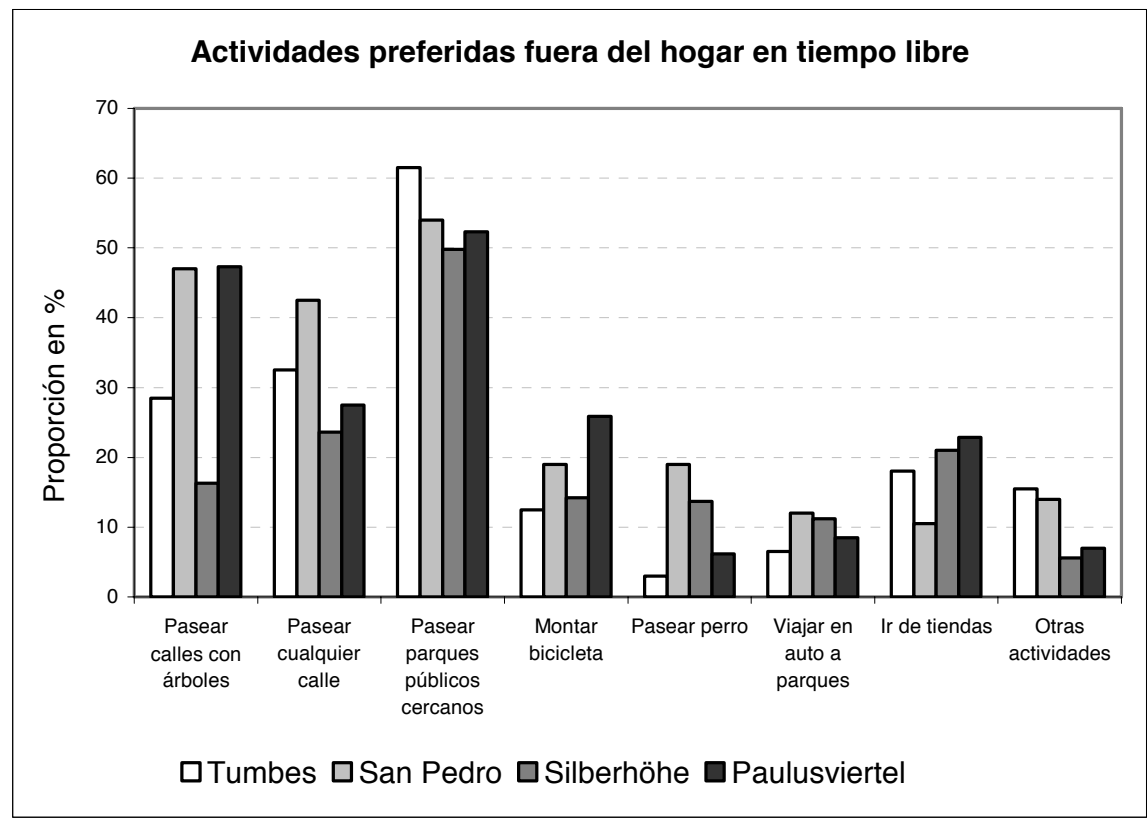

Fuente: Elaboración propia.

menos atractivo en aquéllos pasear por ellas. No obstante, las diferencias entre estos dos barrios de bajos ingresos debe ser explicada, pudiéndose recurrir a la influencia de la variable cultural, más proambientalista entre los chilenos que entre los alemanes. La influencia de la variable socioeconómica es corroborada por las preferencia ante la opción de "pasear por cualquier calle del vecindario", que aumentan en el caso de los barrios de menos nivel socioeconómico (sube al 33\% esta opción respecto a la anterior en Tumbes, y al $24 \%$ en Silberhöhe) y disminuyen en los de más nivel de renta (baja al 43\% esta opción respecto a la anterior en San Pedro de la Paz, y al 27\% en Paulusviertel). Para explicar las diferencias entre los barrios chilenos y alemanes controlando el nivel socioeconómico, habría que recurrir de nuevo a la variable cultural.

Respecto a la observación de la naturaleza por parte del ciudadano, puede suceder en muchos momentos diferentes del día: unas veces, de forma involuntaria; y otras, de forma intencionada. Para tener un mayor conocimiento acerca de cómo entran los ciudadanos en contacto con la naturaleza se les hizo la pregunta siguiente: "¿Cuándo suele usted observar la naturaleza?". La respuesta mayoritaria en los dos países fue: "cuando se camina por la ciudad para hacer alguna diligencia" (San Pedro de la Paz $66 \%$, Tumbes $32 \%$, Paulusviertel $77 \%$ y Silberhöhe $65 \%$ ) (gráfico 6). 
Gráfico 6.

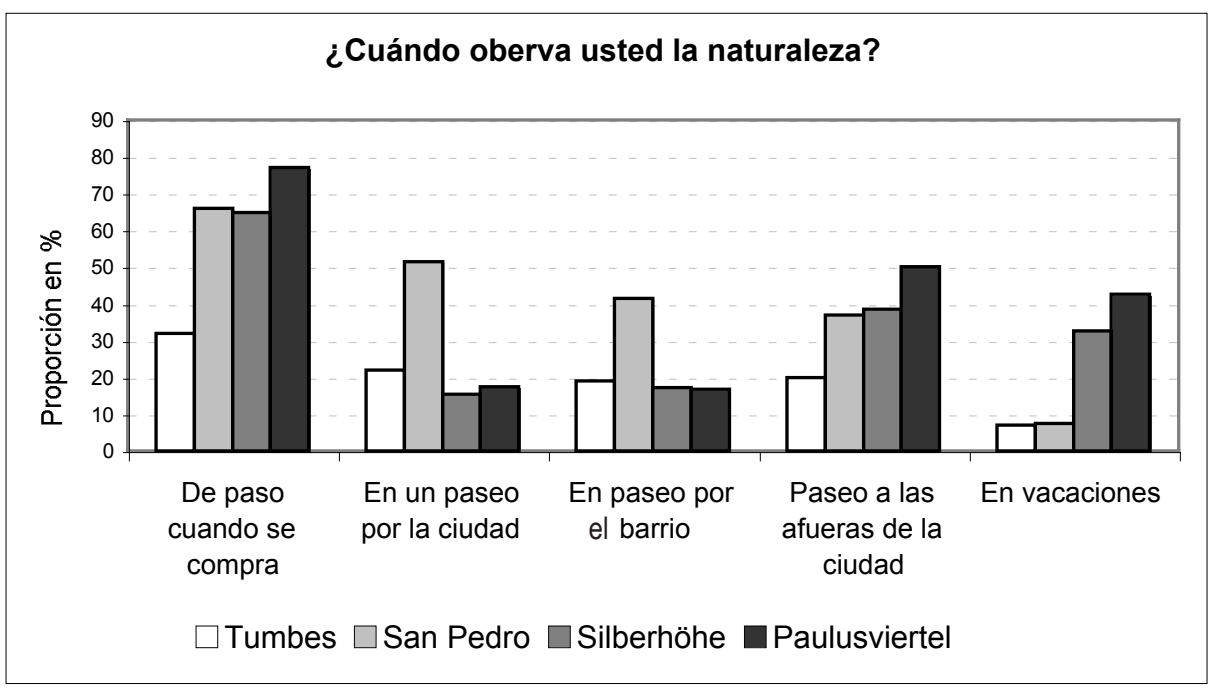

Fuente: Elaboración propia.

Si bien, tanto en Chile como en Alemania, la mayoría de las veces se observa la naturaleza de paso, es decir, de forma no intencionada, resulta, una vez más, que es el barrio chileno más pobre (Tumbes) el que arroja el porcentaje más bajo, lo que podría explicarse por el hecho de no contar con espacios verdes en sus calles. Esta deficiencia apenas se nota en el barrio obrero alemán de Silberhöhe, tal vez porque sus residentes disponen de los ya comentados jardines de uso privado en el barrio o porque usan con más frecuencia el automóvil permitiéndoles salir del barrio para realizar sus compras.

En Alemania, la mayoría de los viajes en automóvil tienen lugar en el tiempo libre. La relación con los automóviles privados influye en la forma como se observan y aprovechan los espacios naturales, ya que aumenta las posibilidades de llegar a lugares que sería impensable visitar de otro modo. En las zonas alemanas, casi dos tercios de los encuestados (56\%) tienen uno o dos automóviles, y las diferencias no son significativas entre Paulusviertel (57\%) y Silberhöhe (54\%). En las zonas de investigación chilenas, mucho menos habitantes disponen de automóvil, existiendo diferencias significativas entre los barrios según el nivel socioeconómico de cada área de residencia: Tumbes (9\%) y San Pedro de la Paz (57\%). Estas diferencias sociales entre los barrios chilenos repercuten en el contacto personal con la naturaleza, ya que las familias más desfavorecidas, además de contar con menos espacios verdes en sus barrios, no disponen de vehículo propio para salir y disfrutar de tales espacios de esparcimiento. 
Aunque se presenta en nuestra vida diaria de múltiples formas y expresiones, la naturaleza suele manifestarse en las ciudades en forma de jardines, parques o ríos urbanos e incluso en las flores de nuestro balcón o terraza. Sin embargo, ese concepto de naturaleza urbana -ordenada 0 , como sugieren muchos diseñadores urbanos, "planificada"- no es entendida como tal por muchos ciudadanos que, viviendo en barrios bien dotados de espacios verdes, no perciben la presencia de la naturaleza en su entornos. En Alemania, por ejemplo, donde los barrios disponen de zonas verdes, gran parte de la población dice observar la naturaleza en "vacaciones" (en Paulusviertel un $43 \%$ así lo percibe, y en Silberhöhe un 33\%) o en "áreas verdes alejadas de la ciudad" (50\% en Paulusviertel y $39 \%$ en Silberhöhe) y no "cuando se pasea por la ciudad o por el barrio". En Tumbes, que es el barrio más pobre de los cuatro, el porcentaje de ciudadanos que dice observar la naturaleza es el más bajo, lo cual podría explicarse por la escasa presencia de espacios naturales en sus calles, por el escaso tiempo que tienen sus habitantes para pasear o por la falta de recursos económicos para irse de vacaciones o viajar.

Cuando la población decide salir de casa y dar un paseo, gran parte de la población decide ocupar ese tiempo en contacto con la naturaleza. Es en estas ocasiones cuando las áreas verdes públicas cobran una gran importancia, ya que más de la mitad de los

\section{Gráfico 7.}

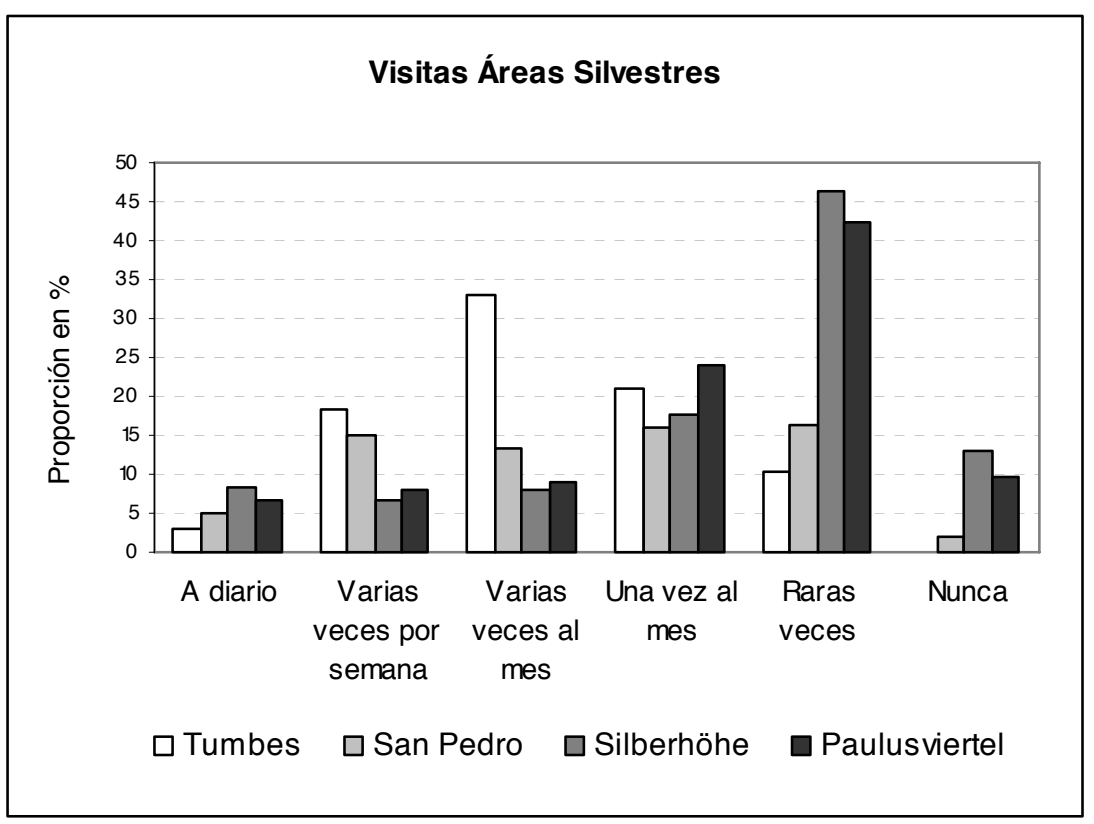

Fuente: Elaboración propia. 
residentes en los cuatro barrios seleccionados dicen disfrutar de ellas. Se observan diferencias por razones culturales y de estructura de oportunidades, más que por razones socioeconómicas. En efecto, en los barrios chilenos son mayores los porcentajes de encuestados que dicen ir con frecuencia a los parques urbanos, que en los alemanes: San Pedro de la Paz (38\%), Tumbes (35\%), Paulusviertel (22\%) y Silberhöhe (10\%). Si se comparan los dos barrios de mayor nivel socioeconómico vemos que, en el chileno de San Pedro de la Paz se va con más frecuencia a los parques urbanos que en el de Paulusviertel, en cuya explicación debe intervenir la mayor cultura proambiental de los chilenos, pero también el hecho de que los alemanes disponen de mayores oportunidades para gozar de la naturaleza en sus hogares al tener jardines propios o jardines públicos de uso privado (los Allotment Gardens ya citados).

Para profundizar en este aspecto se les formuló a los encuestados la siguiente pregunta: “¿Suele usted realizar visitas de larga duración a las zonas verdes urbanas?". Fue mayor el porcentaje de chilenos que dijeron que "frecuentemente" solían visitar los espacios urbanos por un largo periodo de tiempo, que los alemanes: $42 \%$ en San Pedro de la Paz y $36 \%$ en Tumbes, frente al $26 \%$ en Paulusviertel y al $14 \%$ en Silberhöhe. Sin embargo, la opción más citada por los alemanes fue la de visitar los parques urbanos "una o dos veces al mes": $43 \%$ en Paulusviertel y 50\% en Silberhöhe, frente al $36 \%$ en San Pedro de la Paz y el $31 \%$ en Tumbes. Estos datos muestran la importancia de la variable cultural, pero también la incidencia de la variable socioeconómica (a mayor nivel de renta, mayor es la frecuencia con la que se visitan los parques urbanos).

El menor uso de los espacios verdes públicos por los alemanes no se ve compensado por un mayor aprovechamiento de otros espacios naturales alternativos, como por ejemplo las áreas silvestres situadas en los alrededores de la ciudad. Sin embargo, los chilenos muestran una clara disposición a usar esos espacios de naturaleza silvestre, lo que, unido a su alta disposición a visitar los parques urbanos, muestra la influencia de la cultura proambiental en su comportamiento. En efecto, ante la pregunta sobre el "uso de las áreas silvestres que se encuentran en los alrededores de la ciudad", la mayoría de los alemanes dice que "en raras ocasiones" o "nunca" visita estas áreas silvestres (un $57 \%$ en Paulusviertel y un $52 \%$ en Silberhöhe), mientras que en los barrios chilenos esos porcentajes son mucho más bajos (un $18 \%$ en San Pedro de la Paz y un $12 \%$ en Tumbes) (gráfico 7). Sin embargo, en los barrios chilenos los encuestados que dicen visitar con frecuencia (sea a diario, una o varias veces al mes o a la semana") esas áreas de naturaleza silvestre son mayoritarios (un $76 \%$ en Tumbes y un $50 \%$ en San Pedro de la Paz), mientras que en los barrios alemanes descienden esos porcentajes sensiblemente (un 40\% en Paulusviertel y un 39\% en Silberhöhe).

La elevada frecuencia de visitas de los chilenos a estas áreas podría explicarse por la variable cultural, si bien en el caso del barrio de escasos recursos de Tumbes hay una clara influencia de la variable socioeconómica, debido, quizás, a la necesidad que tienen muchos de sus habitantes de sacarse un dinero extra para la subsistencia de la familia mediante la saca de madera (para cocinar y calentar la casa) o la recolección de productos silvestres ("tierra de hojas") en estas áreas para luego venderlos. 
En definitiva, independientemente de su estrato social, los chilenos tienen un mayor contacto con los espacios verdes públicos que los alemanes, tanto en lo que se refiere a las áreas de sus propios barrios, como las que se encuentran en la periferia de las ciudades. Sin embargo, los habitantes de Tumbes, quizás debido a la carencia de vegetación urbana en su barrio y las necesidades económicas, usan con mayor frecuencia los espacios silvestres periféricos. En Alemania, el contacto con la naturaleza es más bien privado, ya que estos prefieren disfrutar más de los jardines de uso privado 0 de las parcelas de fin de semana.

\section{CONCLUSIONES}

El interés por los espacios verdes urbanos radica en la importancia que las cuestiones paisajísticas están teniendo en el debate público sobre la habitabilidad de las grandes ciudades y su influencia en las relaciones entre vecinos y la identidad social de las comunidades. Diversos estudios señalan que la presencia de zonas verdes en los barrios o la existencia de parques y jardines públicos es un elemento que contribuye a mejorar el estado de bienestar físico y mental de la población, a favorecer la interacción social y, en definitiva, a hacer más habitables las ciudades liberando las tensiones de la vida cotidiana.

Si bien la UE ha elaborado un conjunto de criterios para ayudar a la introducción de esta dimensión social de la sostenibilidad en el planeamiento urbano, queda pendiente la realización de estudios específicos que permitan analizar la influencia de las variables socioeconómicas o culturales en la percepción, actitudes y comportamiento de la población respecto a los espacios verdes urbanos. De los resultados de tales estudios se podrá determinar qué tipo de espacios verdes son los más apropiados en razón de las características socioeconómicas o culturales de cada barrio.

En este artículo hemos presentado algunos resultados de una investigación realizada en dos barrios de Chile (la rica comuna de San Pedro de la Paz y la más pobre de Tumbes-Talcahuano) y dos de Alemania (el barrio residencial de clase media de Paulusviertel y el barrio obrero de Silberhöhe), con el objetivo de comprobar la influencia de las variables cultural y socioeconómica en la interacción de sus habitantes con el medio ambiente urbano. Dado el reducido tamaño de la muestra utilizada en la encuesta, el producto del estudio es de carácter exploratorio, lo que no quita valor a las conclusiones si se saben interpretar adecuadamente y se evita la osadía de pretender establecer generalizaciones empíricas sobre la base de los resultados obtenidos en la investigación.

Se aprecia la influencia de la variable socioeconómica en la conciencia ambiental de los ciudadanos (a mayor renta, más preocupación por el medio ambiente), pero su sentido no es el mismo en el uso de los espacios verdes públicos, ya que las familias de mayor nivel de renta suelen vivir en hogares que disponen de jardines privados y, por tanto, son menos proclives a la utilización de aquellos otros de carácter público. 
Asimismo, se observa cómo la variable cultural influye en esos aspectos de la conciencia ambiental, pero no en el sentido de los valores postmaterialistas o de los valores políticos apuntados por los autores que estudian la influencia de las políticas de desarrollo sostenible ligadas al Estado del Bienestar. A la luz de los resultados de nuestro estudio, creemos que la influencia de la cultura se produce en un sentido más antropológico, es decir, más profundo y menos coyuntural, ligado a la relación tradicional de cada país con la naturaleza y el medio ambiente.

\section{REFERENCIAS BibLIOGRÁFICAS}

Akbari, N., S. Davis, S. Dorsano, J. Huang y S. Winnett. eds., 1992. Cooling our Communities: A guidebook on tree planting and light-coloured surfacing. Washington, DC: USEPA.

Anderson, L. M. y H. K. Cordell. 1988. "Influence of Trees on Residential Property Values in Athens, Georgia (USA): A Survey Based on Actual Sales Prices". Landscape and Urban Planning. 15: 153-164.

Austin, M.E. 2004. "Resident Perspectives of the Open Space Conservation Subdivision in Hamburg Township". Landscape and Urban Planning. 69: 245-253.

Baker, L., D. Hope, J. Edmonds y L. Lauver. 2001. "Nitrogen Balanced for the Central Arizona-Phoenix (CAP) Ecosystem". Ecosystem. 4: 582-602.

Beer, A. R. 1994. "Urban Greenspace and Sustainability". En Sustainable Urban Development: Research and Experiments, H.Van der Vecht et al., pp. 69-88. Holanda: Delft University Press.

Benzeval, M. K. Judge y M. Whitchcad. 1995. Tackling Inequalities in Health. Londres: Kings Fund.

Berman, L. 1997. How does our Garden Grow? A Guide to Community Garden Success. Toronto: FoodShare Metro.

Breuste, J. y S. Wohlleber 1998. "Naturschutz und Landschaftspflege in urbanen Kulturlandschaften Leipzigs". Zeitschrift für den Erdkundeunterricht. 50: 215-225.

Bruson, L., F. E. Kuo y W.C. Sullivan. 1998a. Sowing the seeds of community: greening and gardening in inner-city neighbourhoods. Unpublished manuscript.

Bruson, L., F. E. Kuo y W.C. Sullivan. 2001. "Resident appropriation of defensible space in urban public housing: Implications for safety and community". Environment \& Behaviour. 335: 626-652.

Bussey, S. C. 1996. Public Uses, Preferences and Perceptions of Urban Woodlands in Redditch. Unpublished PhD thesis. University of Central England in Birmingham: UK.

Chenoweth, R. E. y P. H. Gobster. 1990. "The Nature and Ecology of Aesthetic Experiences in the Landscape". Landscape Journal. 9: 1-18.

Chiesura, A. 2004. "The Role of Urban Parks for the Sustainable City". Landscape and Urban Planning. 68: $129-138$. 
Coles, R.W. y S.C. Bussey. 2000. "Urban Forest Landscapes in the UK, Progressing the Social Agenda". Landscape \& Urban Planning. 52: 181-188.

Douglas, I. 1983. The Urban Environment. Londres: Arnold.

Dwyer, J.F.E.G. McPherson, H. W. Schoeder y R. A. Rowntree. 1992. "Assessing the Benefits and Costs of the Urban Forest". Journal of Arboriculture. 185: 227-234.

Dwyer, J. F. 1995. The Human Dimensions of Urban Forest Ecosystem Management, in Kollin, C. y M. Barratt, eds., pp. 12-16. Nueva York: Proceedings of the 7th National Urban Forest Conference.

Friedrichs, W. 1992. Methoden der Empirischen Socialforschung. 10 Aufl-Opladen 1982.

Garrido, F. 2000. "La Política Medioambiental de la UE. Sus Orígenes, Evolución e Instrumentos de Aplicación". En Siglo XXI. Siglo de la Tierra, Navarro, C. coord., pp. 209-245. Córdoba: Instituto de Estudios Transnacionales INET.

Hester, R.T. 1984. Planning Neighbourhood Space with People, ed. Nueva York: Van Nostrand Reinhold.

Hills, J. 1995. Inquiry Into Income and Wealth. vol. 2. Nueva York: Joseph Rowntree Foundation.

Hough, M.1989. City Form and Natural Process. Londres: Routledge.

Inglehart, R. 1991. El cambio cultural en las sociedades industriales avanzadas. Madrid: CIS.

Jacobs, J. 1961. Death and Life of Great American Cities. Toronto: Random House.

Jon, L. 1989. Estructura urbana y diferenciación residencial. El caso de Bilbao. Madrid: CIS.

Kaplan, R. 1993. "Urban Forestry and the Workplace". En Managing Urban and High use Recreation setting, Gobster, P.H. ed., pp. 41-45. Chicago: USA Forest Service, General Technical Report NC-163.

Kromrey, H. 1991. Empirische Sozialforschung: Modelle und Methoden der Daternerhebung und Datenauswertung.-5. Aufl.- Opladen=UNI-Taschenbücher 1040.

Kuo, F. E., W.C. Sullivan, R. L. Coley y L. Brunson. 1998a. "Fertile Ground for Community: Inner-City Neighbourhood Common Spaces". American Journal of Community Psychology. 26: 823-851.

Kuo, F. E., M. Bacaicoa y W. C. Sullivan. 1998b. "Transforming Inner City Landscapes: Trees, Sense of Safety, and Preferences". Environment and Behaviour. 130: 28-59.

Kuo, F. E. y W. C. Sullivan. 1999. Do Trees Reduce Crime, Domestic Violence? Unpublished manuscript.

Kuo, F. E. y W. C. Sullivan. 2001. "Environment and Crime in the Inner City: Does Vegetation Reduce Crime?". Environment and Behaviour. 33: 343-367.

Lewis, C.A. 1992. "Effects of Plants and Gardening in Creating Interpersonal and Community WellBeing". En The Role of Horticulture in Human Well-Being and Social Development: A National Symposium. Relf, D. ed., pp. 55-65. Portland: Timber Press. 
Lewis, C.A. 1996. Green Nature, Human Nature. The Meaning of Plants in Our Lives. Chicago: University of Illinois Press.

MacDonald, L. 1996. "Global Problems, Local Solutions: Measuring the Value of the Urban Forest". American Forests. 103:26-32.

McDonnell, M.J., S.T.A. Pickett, R.V. Pouyat, W.C. Zipperer, R. W. Parmelee, M. M. Carreiro y K. Medley. 1997. "Ecosystem Processes Along an Urban-to-Rural Gradient". Urban Ecosystems. 1: 21-36.

McPherson, E.G. 1991. Environmental Benefits and Costs of the Urban Forest. En Robdell, P. D. ed., Proceedings of the Fifth National Urban Forest Conference: Los Ángeles.

McPherson, E. G., D. Nowak, G. Heisler, S. Grimmond, C. Souch, R. Grant y R. Rowntree. 1995. "Results of the Chicago Urban Forest Climate Project". En Proceedings of the 7th National Urban Forest Conference, Kollin, C. y M. Barratt, eds., Nueva York.

Miles, I. W., C. Sullivan y F. E. Kuo. 1998. "Ecological Restoration Volunteers: The Benefits of Participation." Urban Ecosystems. 2: 27-41.

Moyano, E. y M. Jiménez-Sánchez. 2005. Los andaluces y el medio ambiente. Ecobarómetro de Andalucía. Sevilla: Consejería de Medio Ambiente, Junta de Andalucía.

Nowak, D. J. K. L. Civerolo, S. T. Rao, S. Sistla, C. J. Luley y D. E. Crane. 2000. "A Modelling Study of the Impact of Urban Trees on Ozone". Atmospheric Environment. 34: 1601-1613.

Pacione, M. 2003. "Urban Environmental Quality and Human Wellbeing. A Social Geographical Perspective". Landscape and Urban Planning. 65: 19-30.

Park, R.1915. "The City: Suggestions for the Investigation of Human Behaviour in the city Environment". American Journal of Sociology. 20: 577-612.

Peck, S. W. y C. Callaghan. 1999. Greenbacks from Green Roofs: Forging a New Industry in Canada. Ottawa: Canadian Mortgage and Housing Corporation.

Prescott-Allen, R.1991. "Caring for the Earth: A Strategy for Sustainable Living". IUCN, The World Conservation Union, United Nations Environmental Program, Worldwide Fund for Nature. Gland, Suiza.

Rohde, CLE y A. D. Kendle. 1994. Human Well-being. Natural Landscapes and Wildlife in Urban Areas. A review. English Nature: Peterborough.

Santibáñez, F. y J.M. Uribe. 1993. Atlas Agroclimático de Chile. Regiones Sexta, Séptima, Octava y Novena. Universidad de Chile y Ministerio de Agricultura: Ciudad de Chile.

Sebba, R. 1991. "The Landscape of Childhood: the Reflection Childhood s Environment in Adult Memories and in Children's Attitudes". Environment Behavior. 395-422.

Selia, A.F. y L. M. Anderson. 1982. "Estimating Costs of Tree Preservation on Residential Lots". Journal of Arboriculture. 8: 182-185. 
Selia, A.F. y L.M. Anderson. 1984. "Estimating Tree Preservation on Urban Residential Lots in Metropolitan Atlanta. Georgia". Forest Service Research Paper. 48: 6.

Stewart, W. P. D. Liebert y K. W. Larkin. 2004. "Community Identities as Visions for Landscape Change". Landscape and Urban Planning. 69: 315-334.

Sukopp, H. y P. Werner. 1983. "Urban Environments and Vegetation". En Zerbe, S., U. Maurer, S. Schmitz y H. Sukopp. 2003. "Biodiversity in Berlin and its Potential for Nature Conservation". Landscape and Urban Planning. 62: 139-148.

Tyrvainen, I. y H. Vaananen. 1998. "The Economic Value of Urban Forest Amenities: An Application of the Contingent Valuation Methods". Urban Planning. 43: 105-118.

Ulrich, R.S. 1976. "Visual Landscape and Psychological Well-being”. Landscape Research. 4: 17-23.

Ulrich, R.S. 1984. "View Through a Window may Influence Recovery from Surgery". Science. 224: 420-421.

Yearly, S. 1992. The Green Case. A Sociology of Environmental Issues. Arguments and Politics. Londres: Routledge.

CARLOS PRIEGO GONZÁLEZ DE CANALES. Licenciado en Ciencias Biológicas por la Universidad de Córdoba. Doctor en Ciencias Ambientales por la Universidad de Concepción, Chile y Diplomado en Análisis y Gestión del Ambiente por el Centro Internacional de Estudios Ambientales EULA-CHILE (Chile). De 2000 a 2002 trabajó en el Departamento de Planificación Territorial del Centro EULA-CHILE, y durante 2003 en el Departamento de Paisaje Urbano del Instituto UFZ-Umweltforschungszentrum Leipzig-Halle (Alemania). Su área de investigación es la Ecología Urbana, los Espacios Verdes Urbanos y la Sociología Ambiental.

JÜRGEN BREUSTE. Geógrafo, Doctor en Geografía Física por la Universidad Martin-Luther de Halle, Alemania. Director y Profesor del Departamento de Geografía y Geoinformática de la Universidad de Paris-Lodron de Salzburgo (Austria). Miembro y Presidente de numerosas instituciones internacionales de reconocido prestigio en el campo de la Ecología Urbana. En la actualidad dirige el grupo de investigación de Paisajes Urbanos de la Universidad Paris-Lodron de Salzburg (Austria), con numerosos proyectos repartidos por todo el mundo.

JORGE ROJAS HERNÁNDEZ. Sociólogo, Doctor en Sociología, Universidad de Hannover, Alemania. Investigador y docente del Instituto de Sociología de la Universidad de Hannover (1983-1993), Alemania. Profesor Titular del Departamento de Sociología y Antropología de la Universidad de Concepción. Subdirector de formación e investigación del Centro de Ciencias Ambientales EULA (19942004). Actualmente es Decano de la Facultad de Ciencias Sociales de la Universidad de Concepción. Especialista en teoría social, trabajo, desarrollo y medio ambiente.

RECIBIDO: $14 / 05 / 08$

ACEPTADO: $26 / 11 / 08$

Publicado on-line: 18 de diciembre de 2009 